\title{
Memory Function in Feeding Habit Transformation of Mandarin Fish (Siniperca chuatsi)
}

\author{
Yaqi Dou, Shan He *, Xu-Fang Liang *, Wenjing Cai, Jie Wang, Linjie Shi and Jiao Li \\ College of Fisheries, Chinese Perch Research Center, Huazhong Agricultural University, No.1, Shizishan Street, \\ Hongshan District, Wuhan, Hubei Province, 430070, China; Freshwater Aquaculture Collaborative Innovation \\ Center of Hubei Province, Key Lab of Freshwater Animal Breeding, Ministry of Agriculture, Wuhan 430070, \\ China; douyaqi@outlook.com (Y.D.); wenjing_caicai@163.com (W.C.); scofield_wj@163.com (J.W.); \\ shilinjie824@163.com (L.S.); lijiao0519@foxmail.com (J.L.) \\ * Correspondence: heshan@mail.hzau.edu.cn (S.H.); xufang_liang@hotmail.com (X.-F.L.); \\ Tel.: +86-27-8728-8255 (S.H. \& X.-F.L.); Fax: +86-27-8728-2114 (S.H. \& X.-F.L.)
}

Received: 20 January 2018; Accepted: 10 April 2018; Published: 22 April 2018

\begin{abstract}
Mandarin fish refuse dead prey fish or artificial diets and can be trained to transform their inborn feeding habit. To investigate the effect of memory on feeding habit transformation, we compared the reaction time to dead prey fish and the success rate of feeding habit transformation to dead prey fish with training of mandarin fish in the 1st experimental group (trained once) and the 2nd experimental group (trained twice). The mandarin fish in the 2nd group had higher success rate of feeding habit transformation (100\%) than those in the 1st group $(67 \%)$, and shorter reaction time to dead prey fish $(<1 \mathrm{~s})$ than those in the 1st group $(>1 \mathrm{~s})$. Gene expression of cAMP responsive element binding protein I (Creb I), brain-derived neurotrophic factor (Bdnf), CCAAT enhancer binding protein delta (C/EBPD), fos-related antigen 2 (Fra2), and proto-oncogenes $c$-fos ( $c$-fos) involved in long-term memory formation were significantly increased in the 2nd group after repeated training, and taste 1 receptor member 1 (T1R1), involved in feeding habit formation, was significantly increased in brains of the 2nd group after repeated training. DNA methylation levels at five candidate CpG (cytosine-guanine) sites contained in the predicted CpG island in the $5^{\prime}$-flanking region of T1R1 were significantly decreased in brains of the 2 nd group compared with that of the 1st group. These results indicated that the repeated training can improve the feeding habit transformation through the memory formation of accepting dead prey fish. DNA methylation of the T1R1 might be a regulatory factor for feeding habit transformation from live prey fish to dead prey fish in mandarin fish.
\end{abstract}

Keywords: mandarin fish (Siniperca chuatsi); memory; feeding habit transformation; training; repeated training; DNA methylation

\section{Introduction}

Animal feeding habits and feed-preferences not only affect growth characteristics and living habits, but also determine the aquaculture production costs and economic benefits. Although animal feeding habits and feed composition have been intensively investigated, little attention has been devoted to the transformation mechanism of inherent feeding habits of animals, especially in fish. Mandarin fish (Siniperca chuatsi), as a demersal piscivore, have a unique feeding habit. Once the fry of mandarin fish start feeding, they only accept live prey fish in the wild and refuse dead prey fish or artificial diets $[1,2]$. They can be trained to transform their innate feeding habit to accept dead prey fish [3].

Learning and memory could enable the organism to plastically respond to the changing environment. Increasing research has investigated the cognitive (learning) and memory characteristics 
of fish in the past few decades, including antipredator behavior [4-8], spatial cognition (orientation and migration) [9-13], learned recognition [14], social learning [4,15-17], mate choice [18-20], eavesdropping [4], and foraging activity [21,22]. Warburton [21] indicated that learning and memory system can play an important role in the foraging activity of fish. However, we still do not know whether learning and memory can play an important role on feeding habit transformation.

Feeding habit is a congenital behavior characteristic, which might be attributed to the integration of natural inheritance and acquired learning and memory [23,24]. Feeding habits of fish are regulated by a variety of factors, including (1) intrinsic genetic and physiological factors such as appetite and digestive tract structure and (2) external factors such as protein sources, food properties, and feed palatability [25]. Therefore, environmental changes might transform the feeding habit of fish. However, very little is currently known about the epigenetic regulation on learning and memory during feeding habit transformation. In mammals, epigenetic regulation has been reported to be involved in associational fear conditioning [26], extinction of learning fear [27], and spatial memory [28,29]. It has been reported that the experience-dependent epigenetic regulation is involved in long-term memory formation by the regulation of gene transcription [30].

The transcriptome sequencing of food preference in hybrid $\mathrm{F}_{1}$ of Siniperca chuatsi $(\%) \times$ Siniperca scherzeri $\left(\sigma^{\top}\right)$ mandarin fish was analyzed; 1986 and 4526 differentially expressed genes in feeders and nonfeeders (dead prey fish) were identified, respectively. The mRNA levels of proto-oncogenes $c-f o s$ (c-fos), fos-related antigen 2 (Fra2), immediate early gene zif268 (zif268), cAMP responsive element binding protein I (Creb I), CCAAT enhancer binding protein delta (C/EBPD), brain-derived neurotrophic factor $(B d n f)$, and synaptotagmin-IV (SytIV) were significantly decreased in feeders, which might result in significant deficiency in memory retention of their natural food preference [2].

Previous study in mice suggested that taste 1 receptor member 1/3 (T1R1/T1R3) heterodimer might be a sole receptor for umami taste [31,32]. Proteins in the T1R family are expressed not only in taste bud cells in gustatory tissues, but also in the brain, gut, pancreas, and other non-gustatory tissues of various mammalian species [33-37]. Fasting affects expression level of T1R1 in the mouse hypothalamus [35]. The expression of T1Rs in brain leads to an interesting question about their role. Pseudogenization of T1Rs in giant pandas (Ailuropoda melanoleuca) was related to its dietary switch from carnivore to herbivore [38,39]. Nonsynonymous single polymorphisms (nsSNP) in the coding region of T1R1 and T1R3 in humans contributed to the explanation of the inability to taste monosodium glutamate in non-tasters [40,41]. In regulation with gene transcription initiation, DNA methylation of CpG (cytosine-guanine) islands in gene control regions plays a critical role in gene silencing or activation through chromatin remodeling [42]. Therefore, it is necessary to note that the functions of DNA methylation in T1R1 related to feeding habit transformation have not yet been realized.

In the present study, to investigate the effect of memory on feeding habit transformation, we compared the reaction time to dead prey fish and the success rate of feeding habit transformation from live prey fish to dead prey fish of mandarin fish in the 1st experimental group (trained once) and the 2nd experimental group (trained twice). The behavioral parameters, expression of genes involved in learning and memory, and DNA methylation levels in the CpGs of the T1R1 gene involved in feed identification were examined in mandarin fish. This study improves the understanding of molecular mechanisms of learning and memory and the epigenetic regulation during the unique feeding habit transformation in mandarin fish.

\section{Results}

\subsection{Success Rate of Feeding Habit Transformation and Reaction Time to Dead Prey Fish}

After pre-training for 6 days, all mandarin fish have great potentialities to accept dead prey fish. The success rates of feeding habit transformation to dead prey fish in the 1st experimental group (trained once) and the 2nd experimental group (trained twice) were compared. The success rate of feeding habit transformation to dead prey fish was $0.67 \pm 0.01(67 \%)$ in the 1st experimental group, 
and the success rate reached $1.00 \pm 0.00(100 \%)$ in the 2 nd experimental group. The mandarin fish in the 2nd experimental group had a higher $(P<0.05)$ success rate than those in the 1st experimental group (Figure 1). Reaction time to dead prey fish of mandarin fish in the 1st and the 2nd experimental groups were $3.21 \pm 0.21 \mathrm{~s}$ and $0.42 \pm 0.02 \mathrm{~s}$, respectively. The mandarin fish in the 2nd experimental group had shorter $(P<0.05)$ reaction times to dead prey fish $(<1 \mathrm{~s})$ than did those in the 1st experimental group $(>1 \mathrm{~s})$ (Figure 2). Once trained, mandarin fish preyed on dead prey fish faster.

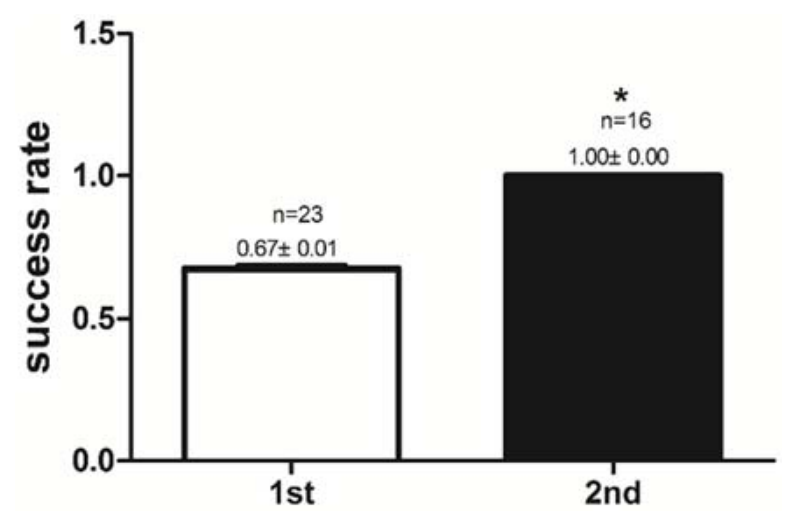

Figure 1. Comparison of the success rate of feeding habit transformation to dead prey fish of mandarin fish in the 1st experimental group (trained once) and the 2nd experimental group (trained twice). All values represent the mean \pm standard error. ${ }^{*}$ indicates significant differences $(P<0.05)$.

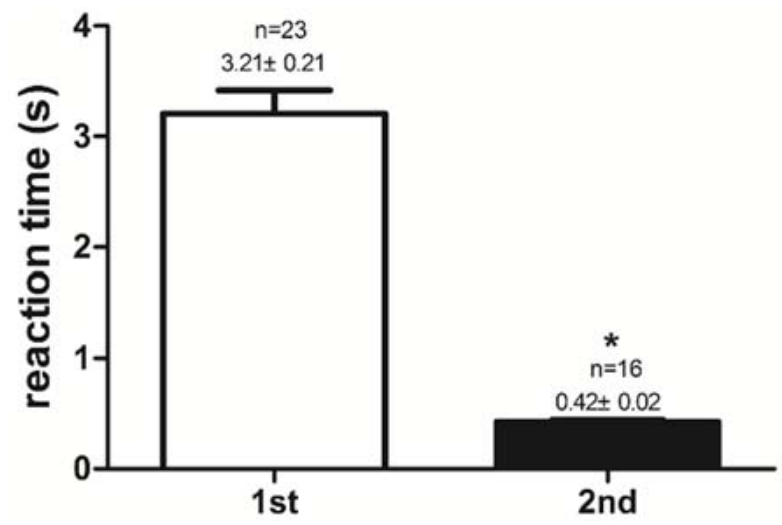

Figure 2. Reaction time(s) to dead prey fish of mandarin fish in the 1st experimental group (trained once) and the 2nd experimental group (trained twice). All values represent the mean \pm standard error. * indicates significant differences $(P<0.05)$.

\subsection{Gene Expression Levels Analysis of Memory-Relative Genes in Mandarin Fish}

As shown in Figure 3, after the first training, gene expression of $C / E B P D, z i f 268$, and $c-f o s$ were significantly increased $(P<0.05)$ in the mandarin fish brains of the 1st experimental group. Compared with the 1st experimental group, the expression levels of Creb I, Bdnf, C/EBPD, Fra2, and c-fos were significantly increased $(P<0.05)$ while the expression levels of zif268 and T1R1 were significantly reduced $(P<0.05)$ in the 2 nd experimental group after repeated training. Compared with the control group, the gene expression of SytIV was significantly increased $(P<0.05)$ in the 2nd experimental group after two trainings. 


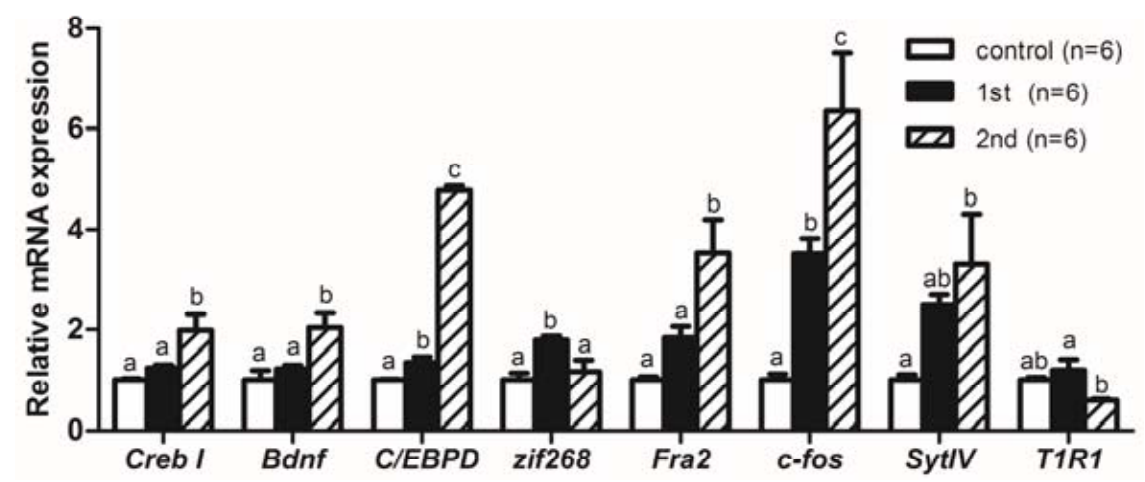

Figure 3. The cAMP responsive element binding protein I (Creb I), brain-derived neurotrophic factor $(B d n f)$, CCAAT enhancer binding protein delta (C/EBPD), immediate early gene zif268 (zif268), fos-related antigen 2 (Fra2), proto-oncogenes $c$-fos (c-fos), synaptotagmin-IV (SytIV), and taste 1 receptor member 1 (T1R1) mRNA expression levels of mandarin fish in the control group, the 1st experimental group (trained once), and the 2nd experimental group (trained twice). The C/EBPD, zif268, and $c$-fos gene expression levels were significantly increased $(P<0.05)$ in the mandarin fish brains of the 1st experimental group compared with those of the control group. The Creb I, Bdnf, C/EBPD, Fra2, and c-fos gene expression levels were significantly increased $(P<0.05)$ and the zif 268 and T1R1 gene expression levels were significantly reduced $(P<0.05)$ in mandarin fish brains of the 2 nd experimental group compared with those of the 1st experimental group. The SytIV gene expression level was significantly increased $(P<0.05)$ in mandarin fish brains of the 2nd experimental group compared with that of the control group. All values represent the mean \pm standard error, a-c indicate significant differences $(P<0.05)$.

\subsection{DNA Methylation Analysis and Bisulphite Sequencing Polymerase Chain Reaction (BSP) of T1R1 Gene}

We analyzed the CpG islands at $-3500 \mathrm{bp}$ upstream from the transcription initiation site (designated as 0) of T1R1 by the methylation analysis software. The prediction of the CpG island, CpG sites, and BSP primers are shown in Figure 4; only one CpG island exists in this region of mandarin T1R1. The full-length of the CpG island is $177 \mathrm{bp}$, the predicted CpG island in the $5^{\prime}$-flanking region from $-3191 \mathrm{nt}$ to $-2894 \mathrm{nt}$ is shown in Figure $4 \mathrm{a}$, and the length of the product is $298 \mathrm{bp}$ encompassing the whole CpG island (Figure $4 \mathrm{~b}$ ). We analyzed the T1R1 gene structure and the distribution of all CpG sites, and the localization of the CpG island are shown in Figure 5. The CpG island contained 9 CpG sites: they are located at $-3085,-3071,-3062,-3049,-3041,-2988,-2981,-2973$, and $-2965 \mathrm{nt}$. Comparison of the DNA methylation levels in brains at the CpG sites in the 1st experimental group (trained once) and the 2nd experimental group (trained twice) is shown in Figure 6. In the 2nd experimental group, the DNA methylation levels in brains at five CpG sites of $-3085,-3062,-3049$, -3041 , and $-2981 \mathrm{nt}$ were significantly lower $(P<0.05)$ than those in the 1st experimental group of mandarin fish (Table 1). 


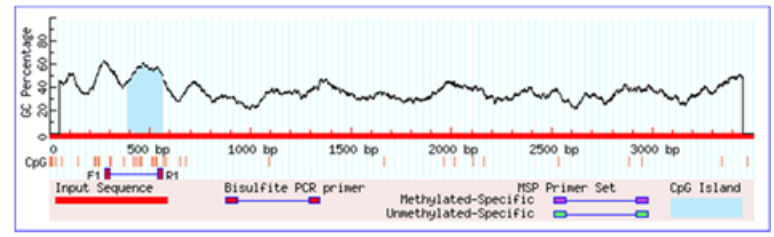

(a)

301 ACTCGTCGCAGGCTMCACAGACACh $|:|++|++:||||:|||:|:||||:|:|||:||||||:|||:||:||||:|:|:|:|:||||:$ 301 ATTCGTCGTAGGGTTAATATAGATATAGATAAGGATAGATAATTATTTATTTTTATATTT

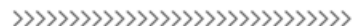

361 ATTCAATACGGGCAATTTAGAGTTATCAATTAACCTACACATGCATGTCTTTGGACGGTG |||:||||++||:|||||||||||||:||||||::||:|:|||:||||:||||||++||| 361 ATTTAATACGGGTAATTTAGAGTTATTAATTAATTTATATATGTATGTTTTTGGACGGTG

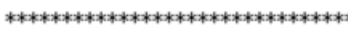

421 GGAGGAAGCCGGAGAACCCGGAGAGAACCCACGGTAACACGGGGAGGACATGCAGACTCC ||||||||$:++|||||::++|||||||:::|++||||:|++|||||||:|||:|||:|:$ : 421 GGAGGAAGTCGGAGAATTCGGAGAGAATTTACGGTAATACGGGGAGGATATGTAGATTTT

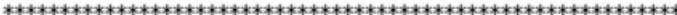

481 ACCCAGAGAGATTGTGTGATGTTGGTCTGGTCCGGGAATCGATCCCACGAACCCACGATC $|:::||||||||||||||||||||||||:||||:++|||||++||:::|++||:::|++||$ : 481 ATTTAGAGAGATTGTGTGATGTTGGTTTGGTTCGGGAATCGATTTTACGAATTTACGATT

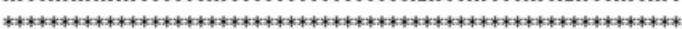

541 TCCTTATTGGGAGGCAGGAGCTTTAGCCGCTCTGCCACCGTGCACCCTTTAATTGATTAT $|::|||||||||||:|||||:|||||:++:|:||::|:++||:|:::||||||||||| \mid$ 541 TITTTATTGGGAGGTAGGAGTTTTAGTCGTTTTGTTATCGTGTATTTTTTAATTGATTAT

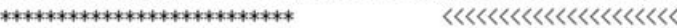

601 TTAGTTGAAATTATTAGTTCTAACTTCTAAAAACAATGATGATAAATTGGTACGATAACT |||||||||||||||||||||||:|||:||:|||||||:|||||||||||||||||||||||++|||||:| 601 TTAGTTGAAATTATTAGTTTTAATTITTAAAAATAATGATGATAAATTGGTACGATAATT «

(b)

Figure 4. Prediction of the $\mathrm{CpG}$ (cytosine-guanine) island, $\mathrm{CpG}$ sites, and bisulphite sequencing polymerase chain reaction (BSP) primers. (a) The results of online prediction software: the full-length of the $\mathrm{CpG}$ island is $177 \mathrm{bp}$, shown in the blue background region. Nine CpG sites and a pair of BSP primers were obtained. CPG sites are shown by the vertical red short lines ' $I$ '. (b) The upper original T1R1 (taste 1 receptor member 1) sequence was compared with the lower bisulfite modified sequence. For display, assume all $\mathrm{CpG}$ sites were methylated and all cytosine was converted into the thymine except for the $\mathrm{CpG}$ sites predicted. $\mathrm{CpG}$ sites, Non-CpG ' $\mathrm{C}^{\prime}$ converted to ' $\mathrm{T}$ ', and the $\mathrm{CpG}$ island are represented by symbols ' ++ ', ' $:$ ', and '*', respectively. The given primers, "BSP1 T1R1 F" and "BSP1 T1R1 R", are represented by symbols ' $>$ ' and ' $<$ ', respectively. (For interpretation of the references to color in this figure legend, the reader is referred to the web version of this article.).

Mandarin fish T1R1

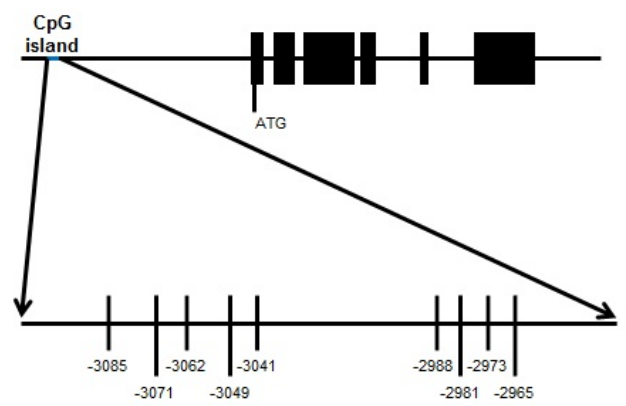

6 Exons, 5 Introns

$1 \mathrm{Kbp}$

Figure 5. Schematic representation of T1R1 (taste 1 receptor member 1) gene structure showing the distribution of all nine CpG (cytosine-guanine) sites and the localization of the CpG island. In the present study, initiation codon ATG (translation start site) is regarded as the ' +1 ' site. The CpG island is located in the $5^{\prime}$-flanking region containing nine $\mathrm{CpG}$ loci marked by Vertical bars. 


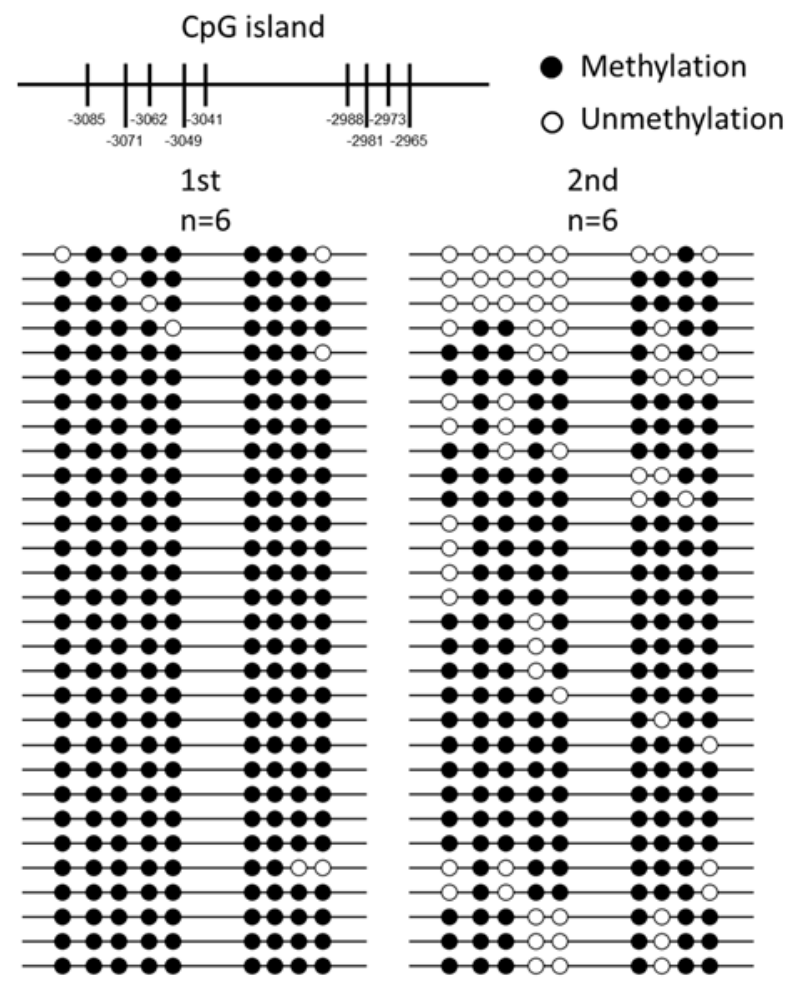

Figure 6. DNA methylation levels at nine candidate $\mathrm{CpG}$ (cytosine-guanine) sites contained in the CpG island in the $5^{\prime}$-flanking region of T1R1 (taste 1 receptor member 1 ) in the 1st experimental group (trained once) and the 2nd experimental group (trained twice). Each line represents one individual bacterial clone, each circle represents a CpG dinucleotide, white circles represent un-methylated CpG sites, and black circles represent methylated $\mathrm{CpG}$ sites.

Table 1. Methylation status of each CpG (cytosine-guanine) site in the CpG island in the $5^{\prime}$-flanking region of T1R1 (taste 1 receptor member 1 ).

\begin{tabular}{ccccccccccc}
\hline $\begin{array}{c}\text { CpG } \\
\text { Position }\end{array}$ & $\mathbf{- 3 0 8 5}$ & $\mathbf{- 3 0 7 1}$ & $\mathbf{- 3 0 6 2}$ & $\mathbf{- 3 0 4 9}$ & $\mathbf{- 3 0 4 1}$ & $\mathbf{- 2 9 8 8}$ & $\mathbf{- 2 9 8 1}$ & $\mathbf{- 2 9 7 3}$ & $\mathbf{- 2 9 6 5}$ & Total \\
\hline Me-CpG & $29 / 30$ & $30 / 30$ & $\mathbf{2 9 / 3 0}$ & $\mathbf{2 9 / 3 0}$ & $\mathbf{2 9 / 3 0}$ & $30 / 30$ & $30 / 30$ & $29 / 30$ & $27 / 30$ & $262 / 270$ \\
st $^{1}(\%)$ & 96.70 & 100.00 & 96.70 & 96.70 & 96.70 & 100.00 & 100.00 & 96.70 & 90.00 & 97.00 \\
\hline $\mathrm{Me}^{2} \mathrm{CpG}$ & $18 / 30$ & $27 / 30$ & $22 / 30$ & $19 / 30$ & $20 / 30$ & $27 / 30$ & $21 / 30$ & $28 / 30$ & $24 / 30$ & $206 / 270$ \\
nd $^{2}(\%)$ & 60.00 & 90.00 & 73.30 & 63.30 & 66.70 & 90.00 & 70.00 & 93.30 & 80.00 & 76.30 \\
\hline significance & $0.007^{*}$ & 0.236 & $0.030 *$ & $0.004^{*}$ & $0.008^{*}$ & 0.236 & $0.004^{*}$ & 1.000 & 0.470 & $0.000^{*}$ \\
\hline
\end{tabular}

${ }^{1}$ The first (fraction) and the second (percentage) lines are for the 1st experimental group (trained once) $(n=6) ;{ }^{2}$ The third (fraction) and forth (percentage) lines are for the 2 nd experimental group (trained twice) $(n=6)$; ${ }^{*}$ indicates significant differences $(P<0.05)$.

\section{Discussion}

To investigate the effect of memory on feeding habit transformation, we compared the success rate of feeding habit transformation to dead prey fish with training of mandarin fish in the 1st experimental group (trained once) and the 2nd experimental group (trained twice). The mandarin fish in the 2 nd experimental group had higher success rates of feeding habit transformation from live prey fish to dead prey fish (100\%) than those in the 1st experimental group $(67 \%)$, and shorter reaction time to dead prey fish $(<1 \mathrm{~s})$ than those in the 1st experimental group $(>1 \mathrm{~s})$. These results indicate that mandarin fish through the first training are much easier and faster to accept dead prey fish during the second training phase. The mandarin fish were able to accept dead prey fish after training, and repeated training promoted the reconsolidation from a labile memory of accepting dead prey fish to a stable 
memory. Mandarin fish accept live prey fish only in the wild and refuses dead prey fish or artificial diets. Systematic physiological studies have been conducted on the sensory basis of food detection of mandarin fish to elucidate the main reasons for mandarin fish refusing artificial diets [43]. Liang, et al. [3] indicated that mandarin fish yearlings could accept dead prey fish or artificial diets during feeding, using a training program based on its feeding specific sensory modality. Importantly, learning processes (trial-and-error learning and imprinting) play a large role in the behavioral patterns of both fish and mammals [23,24]. The newly learned information is unstable and gradually becomes stable and insensitive to disruption in a the process called memory consolidation [44]. Once memory has stabilized, it might be disrupted but could again become temporally labile if reactivated by recall. Reconsolidation is a process which transforms a reactivated memory from a labile form to a stable one $[45,46]$. After the first training, the learned information can be stored in the brain of mandarin fish, and the labile memory of accepting dead prey fish can be transformed to a stable form by reconsolidation, the second training. It is suggested that memory might play an important role in the feeding habit transformation from live prey fish to dead prey fish for mandarin fish.

We also examined the mRNA expression of genes involved in synaptic plasticity as well as memory formation in mandarin fish with the feeding habit transformation. The mRNA expressions of $C r e b I, B d n f$, and C/EBPD genes of mandarin fish in the second training phase (2nd) were significantly increased compared to those in the first training phase (1st). The level of $C / E B P D$ gene expression was also significantly increased in the first training phase compared with that of the control group that was not exposed to dead fish. The transcription factor CREB (cAMP responsive element binding protein) is indispensable for long-term memory formation [47], and Creb hypomorphic mutant mice (Mus musculus) inevitably have impaired spatial and contextual long-term memory formation [48]. Bdnf (Brain-derived neurotrophic factor) is one of the target genes of CREB in rat (Rattus norvegicus) [49]; the mRNA expression of $B d n f$ gene in the hippocampus is up-regulated in rats after spatial training [50] and contextual conditioning [51]. C/EBPs are expressed especially in neurons and participate in long-term synaptic plasticity of potential memory formation in invertebrates (marine snails Aplysia californica) [52,53]. Inhibition of mRNA transcription during training time blocked the long-term memory retention of goldfish (Carassius auratus) when using transcriptional inhibitors [54]. Therefore, the enhanced transcription of $B d n f$ and C/EBPD genes might be a decisive physiological process for memory consolidation and reconsolidation for accepting dead prey fish and contributing to the feeding habit transformation of mandarin fish.

As the downstream signaling molecular of CREB, the expression level of the zif268 gene was significantly reduced in mandarin fish during the second training phase (2nd) compared with that of the first training phase (1st), but the mRNA expressions of Fra2 and c-fos were significantly up-regulated. The level of $c$-fos gene expression was also significantly increased in the first training phase compared with that of the control group that was not exposed to dead fish. Fra2 and c-fos belong to immediate early genes as well as the Fos family of transcription factors, and the mRNA expressions of these two genes are increased as a response to various neuronal activation processes, including long term memory [55]. C-fos is necessary for consolidation of non-spatial hippocampal-dependent memory [56]. Genetic studies in mice have supported that zif268 is critical for memory consolidation and long-lasting memory stabilization [57]. Zif268 knockout mice show impaired long term memories but intact short-term retention [55]. However, the zif268 mutant mice obtain the ability to learn and form memories after overtraining, suggesting that molecular compensation with learning or memory strategies can recover the loss of the zif268 gene [55,58]. Interestingly, the level of zif268 gene expression was significantly up-regulated in the first training phase (1st), but down-regulated in the second training phase (2nd). The basal level of zif268 gene expression is dramatically and rapidly reduced in the brain of vervet monkeys (Cercopithecus aethiops) by systemic administration of N-methyl-D-aspartate receptor antagonists [59] as well as in the brains of rats after monocular deprivation or dark adaptation [60]. 
Compared with the control group, the gene expression of SytIV was significantly increased in the 2nd experimental group after two trainings. SytIV (synaptotagmin-IV) is a membrane trafficking protein; SytIV influences learning and memory by regulating neurotransmitter release and affecting synaptic plasticity [61,62]. Regulation of the BDNF secretion by sytIV is a mechanism that maintains synaptic strength during long-term potentiation in mice [62].

Our results suggest that the increased expression of $B d n f, C / E B P D$, and $F r a 2$ genes can compensate for zif268 down-regulation, and the significantly increased expressions of $B d n f, C / E B P D$, and Fra2 genes of mandarin fish during the second training session might play important roles in memory consolidation of accepting dead prey fish. The behavioral and gene mRNA expression evidence implicating training in learning and memory have revealed a role in the acquisition, consolidation, and subsequent recall of information.

In the present study, compared with the first training phase (1st), the mRNA expression level of the T1R1 gene was significantly reduced in brains compared to that of the second training phase (2nd) after repeated training. The expression of genes T1R1, T1R2, and T1R3 have been detected in different brain regions of mice [35]. The expression of T1Rs in the brain leads to an interesting question about their role. The current nutritional state (such as food deprivation and nutrient excess) regulates expression level of T1R1 in the mouse hypothalamus [35]. The expressions of T1Rs in the brain might be influenced by animal nutrient sensing. Previous studies [63-65] have shown that taste receptors play an important role in the formation of mammalian food habits, and the umami taste receptors T1R1/T1R3 are activated by amino acids, which are preferred tastants. Glutamate binds to nutrient-sensing taste receptor T1R1/T1R3 (L-amino acids) and elicits umami taste, it also regulates the rate of spontaneous firing and functions as a neurotransmitter [66,67]. The brain makes use of nutrient sensing mechanisms that operate in the periphery via taste receptors and downstream signaling molecules [35]. The taste-like signaling mechanisms might be involved in the central regulation in the brain of homeostatic processes. Our results also indicate that the T1R1 expression in the brain might play important roles in the feeding habit transformation of mandarin fish.

As reported, long-term memory has been found to be involved in various tasks, including social transmission of food preference, object recognition, spatial learning, and conditioned taste aversion [68]. DNA methylation could be involved in the precise regulation of gene expression for adaptation to environmental factors [69]. Previous studies on regulatory mechanisms of DNA methylation have been developed in multiple fields, including ecotoxicology, sexual development, and genetic breeding [70-73], while scarcely any studies looked at feeding habits and memory formation [74]. The pseudogenization of T1R1 and nsSNPs in the T1Rs coding region were related to the carnivore-to-herbivore food conversion in giant pandas [38,39] and humans' ability to taste monosodium glutamate $[40,41]$, respectively. We further found that DNA methylation in the control region of the T1R1 gene in the brain might be crucial for the reconsolidation and stabilization of the memory of accepting dead prey fish, i.e., feeding habit transformation of mandarin fish. After repeated training, the mRNA expression level of the T1R1 gene was significantly reduced in the brain, while the methylation levels in the CPG sites of T1R1 were significantly reduced in brains of mandarin fish. Commonly, cytosine-C5 methylation in the $\mathrm{CpG}$ dinucleotides is associated with inhibition of gene expression [75-77]. The mechanisms of transcriptional repression by DNA methylation in vertebrates are (1) inhibition of the combination of specific binding factors with their cognate recognition sequences [78] and (2) chromatin remodeling and modification activities repressed by Methyl-CpG-binding proteins and transcriptional co-repressor molecules [79]. Human telomerase catalytic subunit ( $h T E R T$ ) expression is a limiting factor in telomerase activity, whereas the $h T E R T$ promoter is hypermethylated in telomerase-positive tissues and hypomethylated in telomerase-negative tissues, resulting in a contrast with the common relationship between promoter methylation and transcriptional silencing [80]. Partial hypomethylation in the core promoter is essential for $h T E R T$ expression in spite of methylation preventing binding of the transcriptional repressor CTCF (CCCTC-binding factor) [80]. DNA methylation might play a dual role in some gene transcriptional 
regulation. The complexity of transcriptional regulation of $T 1 R 1$ remains to be explored. There is also a paradox in which promoter-related methylation is inversely correlated with the gene expression, whereas gene-body-related methylation is positively correlated with gene expression [81]. Cytosine methylation in CpG blocks transcription initiation in mammals [82] and transcription elongation in Fungi (Neurospora crassa) [83]. The interpretation of the relationship between DNA methylation and gene transcriptional regulation is based on a particular genomic context. The most common breeding strategy for fish is to lay a large number of eggs at one time and then leave the eggs to develop without parental care. The innate patterns of fish maturation might differ from those of mammals learned from their parents [24]. However, the mechanism of DNA methylation on gene expression modulation in fish remains uncertainly understood. Our results suggest that mandarin fish can establish the long-term memory of accepting dead prey fish after repeated training, which might be attributed to gene expression of T1R1 regulated by DNA methylation in the brain.

In conclusion, mandarin fish through the first training are easier and faster to accept dead prey fish during the second training phase, suggesting that repeated training promotes the reconsolidation from a labile memory of accepting dead prey fish to a stable memory. The expressions of several genes involved in long-term memory formation and feeding habit formation were significantly different in brains of mandarin fish between the first and second trainings. In addition, DNA methylation of the T1R1 gene might be considered as a regulatory factor for feeding habit transformation from live prey fish to dead prey fish in mandarin fish. These results shed new light on the molecular mechanism of feeding habit transformation in mandarin fish, suggesting the important roles of memory on feeding habit formation.

\section{Materials and Methods}

\subsection{Fish and Sample Preparation}

Experimental mandarin fish $(n=30)$ were obtained from the Wuhan Sihui Fisheries Science and Technology Development Co., Ltd. (Wuhan, China). Mandarin fish were 3 months of age with a total length of $21.22 \pm 1.35 \mathrm{~cm}$. Prior to the experiment, each mandarin fish was kept in an independent aquarium $(60 \times 45 \times 45 \mathrm{~cm})$ where it was accommodated to a continuous water filtration system and dissolved oxygen $(7.26-7.86 \mathrm{mg} / \mathrm{L})$, temperature $\left(25 \pm 1^{\circ} \mathrm{C}\right)$, and $\mathrm{pH}(7.11-7.59)$ at constant values. They were fed once daily at 5:30 pm with live India mrigal (Cirrhinus mrigala) juveniles as live prey fish for 2 weeks. A total five live prey fish were placed $20 \mathrm{~cm}$ away from the mandarin fish. Mandarin fish accepted the live prey fish immediately for feed or had no response, and the live prey fish that had not been eated were left in the aquarium. The uneaten live prey fish were removed from all aquariums at 7:30 pm. Each mandarin fish consumed statistically 2-3 live prey fish every day in the adaptation phase. Samples $(n=7)$ were randomly selected from mandarin fish that was not exposed to dead prey fish as the control group.

The live and frozen India mrigal fry were used as live prey fish and dead prey fish, respectively, in this study, and frozen fry were thoroughly unfrozen before feeding.

All experimental procedures followed the "Guidelines for Experimental Animals" of the Ministry of Science and Technology (Beijing, China) and were approved by the Institutional Animal Care and Use Ethics Committee of Huazhong Agricultural University (Wuhan, China). All efforts were made to minimize suffering. This study did not involve endangered or protected species, thus, no specific permissions were required for the described field studies.

\subsection{Experiment Test Phase}

\subsubsection{Pre-Training}

There was pre-training before the formal training. Each mandarin fish was kept in an independent aquarium and fed a maximum number of 3 live or dead prey fish once daily at 5:30 pm. A prey fish 
was placed $20 \mathrm{~cm}$ away from each mandarin fish, and only a single live or dead prey fish individual was allowed into each aquarium at any time. Mandarin fish accepted the live or dead prey fish immediately for feed or had no response for $2 \mathrm{~min}$, then, the live or dead prey fish that had not been eaten was removed from the aquarium. The feeding trial was stopped if the mandarin fish had already accepted 3 prey fish for feed. The trail described above was repeated for a maximum of 10 times. The pre-training was performed for 6 days following the accommodative training methods originally described by Liang, et al. [3] as the experimental culture. We strictly followed the procedures of trained steps as follows: (1) day 1 , live prey fish fed to satiation only; (2) days $2-4$, gradually replacing live prey fish with dead prey fish within the 10 trials day-by-day; (3) days 5-6, only dead prey fish fed. The pre-training phase allowed the mandarin fish to become familiar preying on live or dead prey fish.

\subsubsection{Experiment Training Phase 1}

The first experiment training $(n=23)$ was performed for 6 days followed the pre-training. Each mandarin fish was kept in an independent aquarium and fed a maximum number of 3 prey fish once daily at 5:30 pm. A dead prey fish was placed $20 \mathrm{~cm}$ away from each mandarin fish, and only a single dead prey fish individual was allowed into each aquarium at any time. The feeding habit of mandarin fish was recorded with a digital camera for $2 \mathrm{~min}$. Timing started when the dead prey fish individual was placed into the aquarium. Mandarin fish accepted the dead prey fish immediately for feed or had no response for $2 \mathrm{~min}$. Then, the dead prey fish that had not been eaten was removed from the aquarium. The feeding trial was stopped if the mandarin fish had already accepted 3 dead prey fish for feed. The trial was performed again if the mandarin fish did not eat 3 dead prey fish, and the trail described above was repeated up to 10 times. The reaction time to dead prey fish and the success rate of feeding habit transformation to dead prey fish of mandarin fish were counted from the videos. Regardless of multiple trials, the reaction time for each mandarin fish was recorded as the daily average. As long as at least one dead prey fish was successfully accepted among the trails in the day, the mandarin fish was marked as a successful feeding habit transformer to dead prey fish, whereas the mandarin fish was marked as a failure if it ate no dead prey fish. Samples $(n=7)$ were randomly selected from the remaining mandarin fish for samples of the first training phase as the 1st experimental group (trained once).

\subsubsection{Natural Feed Revert Procedure}

At the end of the first training phase, the rest of the mandarin fish were returned to the natural feeding habits. Mandarin fish were fed with live prey fish for the next 6 days. Then, in the revert procedure, live prey fish were the first choice of mandarin fish when the live and dead prey fish were presented at the same time, which proves that they had reverted to the characteristics of feeding live prey fish.

\subsubsection{Experiment Training Phase 2}

After that, the rest of the mandarin fish $(n=16)$ were under the second round of training phase. The procedure of the second training ( 6 days) was the same as the aforementioned training phase. Samples $(n=7)$ were randomly selected from the remaining mandarin fish for samples of the second training phase as the 2 nd experimental group (trained twice).

No mandarin fish died of natural causes during the training phases. The experiment was recorded with a digital camera and the videos were used for subsequent behavior analysis.

\subsection{Sample Collection}

Seven mandarin fish were randomly selected from both the 1st and 2nd experimental groups, respectively. Six samples of mandarin fish were selected for the gene expression levels analysis and DNA methylation analysis. One mandarin fish in each phase was used as a spare sample. At the end of each training phase, the mandarin fish were deeply anesthetized with MS-222 (Argent Chemical 
Laboratories, Redmond, WA, USA) (200 $\left.\mathrm{mg} \mathrm{L}^{-1}\right)$ about $2 \mathrm{~h}$ after feeding and were killed. The brains of mandarin fish were immediately collected. The mandarin fish brain samples were then frozen in liquid nitrogen and stored at $-80{ }^{\circ} \mathrm{C}$ for RNA and DNA isolation.

\subsection{RNA Isolation and Reverse Transcription}

Total RNA of mandarin fish brains was extracted with Trizol Reagent (TaKaRa, Tokyo, Japan) according to the manual. The purity and quantity of total RNA were determined using the BioTek Synergy 2 luminometer (BioTek, Winooski, VT, USA), and integrity of total RNA was checked using electrophoresis in 2\% agarose gel (Biowest Agarose, Madrid, Spain). The cDNAs were obtained from $1 \mu \mathrm{g}$ total RNA with the Revert Aid ${ }^{\mathrm{TM}}$ Reverse Transcriptase (TaKaRa, Tokyo, Japan) according to the manufacturer's instructions.

\subsection{Gene Expression Levels Analysis of Memory Relative Genes in Mandarin Fish}

To detect mRNA expressions of memory relative genes in mandarin fish, real-time PCR assays were carried out in a quantitative thermal cycler (MyiQ ${ }^{\mathrm{TM}} 2$ Two-Color Real-Time PCR Detection System, BIO-RAD, Hercules, CA, USA). Primers were designed according to the sequences (Table 2). The RPL13A (60S ribosomal protein L13a) gene was used as an endogenous reference to normalize the template amount. All amplifications for each RNA sample were performed in triplicate. Reaction system with $20 \mu \mathrm{L}$ volume consisted of $10 \mu \mathrm{L}$ AceQ qPCR SYBR Green Master Mix (Vazyme Biotech Co., Piscataway, NJ, USA), $1 \mu \mathrm{L}$ of cDNA, $0.4 \mu \mathrm{L}(10 \mu \mathrm{M})$ of each primer (Sangon, Shanghai, China) and $8.2 \mu \mathrm{L}$ of $\mathrm{ddH}_{2} \mathrm{O}$. The PCR cycling parameters were $95^{\circ} \mathrm{C}$ for $3 \mathrm{~min}$, followed by 40 cycles at $95^{\circ} \mathrm{C}$ for $10 \mathrm{~s}, 58^{\circ} \mathrm{C}$ for $30 \mathrm{~s}$ (according to the annealing temperatures of the different primers), and a melt curve step from $65^{\circ} \mathrm{C}$ gradually increasing by $0.5^{\circ} \mathrm{C} \cdot \mathrm{s}^{-1}$ to $95^{\circ} \mathrm{C}$, with acquisition data every $6 \mathrm{~s}$. Gene expression levels were quantified relative to the expression of the RPL13A gene using the optimized comparative $\mathrm{Ct}\left(2^{-\Delta \Delta \mathrm{Ct}}\right)$ value method. The specificity of the primers was determined through sequencing and melting curve of PCR products. The amplification efficiencies of primers were determined by following the instruction of AceQ qPCR SYBR Green Master Mix (Vazyme Biotech Co., Piscataway, NJ, USA).

Table 2. Nucleotide sequences of the primers for real-time PCR.

\begin{tabular}{cc}
\hline Primers Name & Sequences $\mathbf{( 5}^{\prime} \mathbf{-} \mathbf{3}^{\prime} \mathbf{)}$ \\
\hline RTsc Creb I F & ATACACCCTCCCACTTCA \\
RTsc Creb I R & TCTCCTCCACATCCGTTC \\
RTsc Bdnf F & AACTGCCCTCACTCACA \\
RTsc Bdnf R & ACCTCCCTGGCTCTTAT \\
RTsc C/EBPD F & GCAGGAGAAGGCGGATTT \\
RTsc C/EBPD R & CTGGGAAGGCAGGGATGA \\
RTsc zif268 F & GGATCTTGCCGTGCCTCTTG \\
RTsc zif268 R & TTGCGACCGCCGTTCTC \\
RTsc Fra2 F & CAACCAGGACCTCCAGTG \\
RTsc Fra2 R & TCTACGCCTTTCAATCTC \\
RTsc c-fos F & CGATGATGTTTACCGCTTTC \\
RTsc c-fos R & TAGTATCCCAGATTGTCCC \\
RTsc SytIV F & TGTCGGAGGATTAGAACG \\
RTsc SytIV R & CTGAAAGTCCAATGGGTAC \\
RTsc T1R1 F & TGTATTTTTTTGATAGAATAAGAGT \\
RTsc T1R1 R & TAAAAAAACTTAATATAATACTTTTTAAAA \\
RTsc RPL13A F & TATCCCCCCACCCTATGACA \\
RTsc RPL13A R & ACGCCCAAGGAGAGCGAACT \\
\hline
\end{tabular}




\subsection{DNA Methylation Analysis and Bisulphite Sequencing Polymerase Chain Reaction (BSP)}

Six samples of mandarin fish from the first and the second training phases were analyzed, respectively. Genomic DNA was extracted following the standard procedures using TIANamp Genomic DNA Kit (Tiangen, Beijing, China). DNA treatment with sodium bisulphite was performed using the EZ DNA Methylation Kit (Zymo Research, Irvine, CA, USA) according to the manufacturer's protocol. The sequences of T1R1 were obtained and submitted to the online software Methprimer (http:/ / www.urogene.org/cgi-bin/methprimer/methprimer.cgi) to acquire the distribution of CpG islands (CGIs) and candidate CpG loci (The parameters are as follows: Island size $>100 \mathrm{bp}, \mathrm{GC}$ Percent $>50.0 \%$, Observed/Expected $>0.6$ ). The BSP primers were designed by the online MethPrimer software14 and Primer 5.0; sequences of the PCR primers used for amplifying the targeted products are shown in Table 3. The polymerase chain reaction (PCR) was conducted on Biometra Thermo cyclers (Biometra, Göttingen, Germany) by using Taq plus DNA Polymerase (Vazyme Biotech, Nanjing, China). The PCR protocol was $5 \mathrm{~min}$ at $94{ }^{\circ} \mathrm{C}, 45$ cycles of $94{ }^{\circ} \mathrm{C}$ for $30 \mathrm{~s}, 5{ }^{\circ} \mathrm{C}$ annealing for $30 \mathrm{~s}$ (according to the annealing temperatures of the different primers), and $72{ }^{\circ} \mathrm{C}$ for $30 \mathrm{~s}$, with a final extension at $72{ }^{\circ} \mathrm{C}$ for $7 \mathrm{~min}$, ending with $16^{\circ} \mathrm{C}$ for $10 \mathrm{~s}$. The PCR products were gel purified employing the Gel Purification Kit (Sangon, Shanghai, China) and then were subcloned into the pMD18-T clone vector (Takara, Tokyo, Japan). Five positive clones for each subject were randomly selected for sequencing (Sangon, Shanghai, China). A total of 30 bacterial clones were collected and sequenced in each group. The final sequence results were processed by online QUMA (QUantification tool for Methylation Analysis) software (http:/ / quma.cdb.riken.jp/).

Table 3. Nucleotide sequences of the primers for BSP (bisulphite sequencing polymerase chain reaction) amplified and DNA methylation analysis.

\begin{tabular}{cc}
\hline Primers & Sequences $\left(\mathbf{5}^{\prime} \mathbf{- 3}^{\prime} \mathbf{)}\right.$ \\
\hline & Primers for genomic DNA amplicon \\
CPG1 T1R1 F & AGGGCTAACACAGACACAGACAAGGACAGA \\
CPG1 T1R1 R & CAACTAAATAATCAATTAAAGGGTGCAC \\
\hline & Primers for BSP amplicon \\
BSP1 T1R1 F & AGGGTTAATATAGATATAGATAAGGATAGA \\
BSP1 T1R1 R & CAACTAAATAATCAATTAAAAAATACAC \\
\hline
\end{tabular}

\subsection{Statistical Analysis}

The normality of data was assessed by using SPSS 19.0 software (SPSS, Chicago, IL, USA) with the Shapiro-Wilk test. All data were subjected to one-way analysis of variance using SPSS 19.0 software. Differences between the means were tested by Duncan's multiple range test (MRT) after homogeneity of variances was checked. The DNA methylation analyses were determined with the $\chi^{2}$ test. Statistical significance was determined at the $5 \%$ level. All data were presented as mean \pm S.E.M (standard error of the mean).

Acknowledgments: This work was financially supported by the National Natural Science Foundation of China (31602131), the National Basic Research Program of China (2014CB138601), the Wuhan Morning Light Plan of Youth Science and Technology (No. 2017050304010318), and the National Natural Science Foundation of China (31502158).

Author Contributions: Xu-Fang Liang and Shan He conceived and designed the experiments; Yaqi Dou, Jie Wang, Linjie Shi, and Jiao Li performed the experiments; Yaqi Dou, Jie Wang, and Linjie Shi analyzed the data; Yaqi Dou wrote the paper. Yaqi Dou and Wenjing Cai revised the paper.

Conflicts of Interest: The authors declare that they have no conflict of interest. The founding sponsors had no role in the design of the study; in the collection, analyses, or interpretation of data; in the writing of the manuscript, and in the decision to publish the results. 


\section{References}

1. Chiang, I. On the biology of mandarin fish, Siniperca chuatsi of liang-tze lake. Acta Hydrobiol. Sin. 1959, 3, 375-385.

2. He, S.; Liang, X.-F.; Sun, J.; Li, L.; Yu, Y.; Huang, W.; Qu, C.-M.; Cao, L.; Bai, X.-L.; Tao, Y.-X. Insights into food preference in hybrid f1 of Siniperca chuatsi $(\$) \times$ Siniperca scherzeri $\left(\sigma^{\top}\right)$ mandarin fish through transcriptome analysis. BMC Genom. 2013, 14, 601. [CrossRef] [PubMed]

3. Liang, X.; Oku, H.; Ogata, H.; Liu, J.; He, X. Weaning chinese perch Siniperca chuatsi (Basilewsky) onto artificial diets based upon its specific sensory modality in feeding. Aquac. Res. 2001, 32, 76-82. [CrossRef]

4. Brown, C.; Laland, K.N. Social learning in fishes: A review. Fish Fish. 2003, 4, 280-288. [CrossRef]

5. Kelley, J.L.; Magurran, A.E. Learned predator recognition and antipredator responses in fishes. Fish Fish. 2003, 4, 216-226. [CrossRef]

6. Ajemian, M.; Sohel, S.; Mattila, J. Effects of turbidity and habitat complexity on antipredator behavior of three-spined sticklebacks (Gasterosteus aculeatus). Environ. Biol. Fish. 2015, 98, 45-55. [CrossRef]

7. Wund, M.A.; Baker, J.A.; Golub, J.L.; Foster, S.A. The evolution of antipredator behaviour following relaxed and reversed selection in alaskan threespine stickleback fish. Anim. Behav. 2015, 106, 181-189. [CrossRef] [PubMed]

8. Everley, K.A.; Radford, A.N.; Simpson, S.D. Pile-driving noise impairs antipredator behavior of the european sea bass Dicentrarchus labrax. In The Effects of Noise on Aquatic Life II; Springer: Berlin, Germany, 2016; pp. 273-279.

9. Broglio, C.; Rodriguez, F.; Salas, C. Spatial cognition and its neural basis in teleost fishes. Fish Fish. 2003, 4, 247-255. [CrossRef]

10. Odling-Smee, L.; Braithwaite, V.A. The role of learning in fish orientation. Fish Fish. 2003, 4, $235-246$. [CrossRef]

11. Salas, C.; Broglio, C.; Rodríguez, F. Evolution of forebrain and spatial cognition in vertebrates: Conservation across diversity. Brain Behav. Evol. 2003, 62, 72-82. [CrossRef] [PubMed]

12. Davis, V.; Holbrook, R.; Schumacher, S.; Guilford, T.; de Perera, T.B. Three-dimensional spatial cognition in a benthic fish, Corydoras aeneus. Behav. Process. 2014, 109, 151-156. [CrossRef] [PubMed]

13. Meckley, T.D.; Gurarie, E.; Miller, J.R.; Wagner, C.M. How fishes find the shore: Evidence for orientation to bathymetry from the non-homing sea lamprey. Can. J. Fish. Aquat. Sci. 2017, 74, 2045-2058. [CrossRef]

14. Griffiths, S.W. Learned recognition of conspecifics by fishes. Fish Fish. 2003, 4, 256-268. [CrossRef]

15. Hoare, D.; Krause, J. Social organisation, shoal structure and information transfer. Fish Fish. 2003, 4, $269-279$. [CrossRef]

16. Trompf, L.; Brown, C. Personality affects learning and trade-offs between private and social information in guppies, Poecilia reticulata. Anim. Behav. 2014, 88, 99-106. [CrossRef]

17. Cui, R.; Delclos, P.J.; Schumer, M.; Rosenthal, G.G. Early social learning triggers neurogenomic expression changes in a swordtail fish. Proc. R. Soc. B 2017, 284, 20170701. [CrossRef] [PubMed]

18. Milinski, M. Arms races, ornaments and fragrant genes: The dilemma of mate choice in fishes. Neurosci. Biobehav. Rev. 2014, 46, 567-572. [CrossRef] [PubMed]

19. Lehnert, S.J.; Heath, D.D.; Devlin, R.H.; Pitcher, T.E. Post-spawning sexual selection in red and white chinook salmon (Oncorhynchus tshawytscha). Behav. Ecol. 2016, 28, 1-10. [CrossRef]

20. Lehnert, S.J.; Pitcher, T.E.; Devlin, R.H.; Heath, D.D. Red and white Chinook salmon: Genetic divergence and mate choice. Mol. Ecol. 2016, 25, 1259-1274. [CrossRef] [PubMed]

21. Warburton, K. Learning of foraging skills by fish. Fish Fish. 2003, 4, 203-215. [CrossRef]

22. Pike, T.W.; Laland, K.N. Conformist learning in nine-spined sticklebacks' foraging decisions. Biol. Lett. 2010. [CrossRef] [PubMed]

23. Kieffer, J.D.; Colgan, P.W. The role of learning in fish behaviour. Rev. Fish Biol. Fish. 1992, 2, $125-143$. [CrossRef]

24. Provenza, F.D.; Pfister, J.A.; Cheney, C.D. Mechanisms of learning in diet selection with reference to phytotoxicosis in herbivores. J. Range Manag. 1992, 45, 36-45. [CrossRef]

25. Liu, H.; Li, S.; Bai, J. Research advances in gene regulation and genetic improvement of fish feeding. Agric. Sci. Technol. 2015, 16, 2277-2282. 
26. Gräff, J.; Joseph, N.F.; Horn, M.E.; Samiei, A.; Meng, J.; Seo, J.; Rei, D.; Bero, A.W.; Phan, T.X.; Wagner, F. Epigenetic priming of memory updating during reconsolidation to attenuate remote fear memories. Cell 2014, 156, 261-276. [CrossRef] [PubMed]

27. Stafford, J.M.; Raybuck, J.D.; Ryabinin, A.E.; Lattal, K.M. Increasing histone acetylation in the hippocampus-infralimbic network enhances fear extinction. Biol. Psychiatry 2012, 72, 25-33. [CrossRef] [PubMed]

28. Tong, Z.; Han, C.; Luo, W.; Li, H.; Luo, H.; Qiang, M.; Su, T.; Wu, B.; Liu, Y.; Yang, X. Aging-associated excess formaldehyde leads to spatial memory deficits. Sci. Rep. 2013, 3, 1807. [CrossRef] [PubMed]

29. Roth, E.D.; Roth, T.L.; Money, K.M.; SenGupta, S.; Eason, D.E.; Sweatt, J.D. DNA methylation regulates neurophysiological spatial representation in memory formation. Neuroepigenetics 2015, 2, 1-8. [CrossRef] [PubMed]

30. Sweatt, J.D. Experience-dependent epigenetic modifications in the central nervous system. Biol. Psychiatry 2009, 65, 191-197. [CrossRef] [PubMed]

31. Zhao, G.Q.; Zhang, Y.; Hoon, M.A.; Chandrashekar, J.; Erlenbach, I.; Ryba, N.J.; Zuker, C.S. The receptors for mammalian sweet and umami taste. Cell 2003, 115, 255-266. [CrossRef]

32. Yasuo, T.; Kusuhara, Y.; Yasumatsu, K.; Ninomiya, Y. Multiple receptor systems for glutamate detection in the taste organ. Biol. Pharm. Bull. 2008, 31, 1833-1837. [CrossRef] [PubMed]

33. Mace, O.J.; Lister, N.; Morgan, E.; Shepherd, E.; Affleck, J.; Helliwell, P.; Bronk, J.R.; Kellett, G.L.; Meredith, D.; Boyd, R. An energy supply network of nutrient absorption coordinated by calcium and $1 \mathrm{r}$ taste receptors in rat small intestine. J. Physiol. 2009, 587, 195-210. [CrossRef] [PubMed]

34. Nakagawa, Y.; Nagasawa, M.; Yamada, S.; Hara, A.; Mogami, H.; Nikolaev, V.O.; Lohse, M.J.; Shigemura, N.; Ninomiya, Y.; Kojima, I. Sweet taste receptor expressed in pancreatic beta-cells activates the calcium and cyclic amp signaling systems and stimulates insulin secretion. PLoS ONE 2009, 4, e5106. [CrossRef] [PubMed]

35. Ren, X.; Zhou, L.; Terwilliger, R.; Newton, S.S.; Araujo, I.E.D. Sweet taste signaling functions as a hypothalamic glucose sensor. Front. Integr. Neurosci. 2009, 3, 12. [CrossRef] [PubMed]

36. Treesukosol, Y.; Smith, K.R.; Spector, A.C. The functional role of the t1r family of receptors in sweet taste and feeding. Physiol. Behav. 2011, 105, 14-26. [CrossRef] [PubMed]

37. Voigt, A.; Bojahr, J.; Narukawa, M.; Hübner, S.; Boehm, U.; Meyerhof, W. Transsynaptic tracing from taste receptor cells reveals local taste receptor gene expression in gustatory ganglia and brain. J. Neurosci. Off. J. Soc. Neurosci. 2015, 35, 9717-9729. [CrossRef] [PubMed]

38. Li, R.; Fan, W.; Tian, G.; Zhu, H.; He, L.; Cai, J.; Huang, Q.; Cai, Q.; Li, B.; Bai, Y. The sequence and de novo assembly of the giant panda genome. Nature 2010, 463, 311. [CrossRef] [PubMed]

39. Zhao, H.; Yang, J.-R.; Xu, H.; Zhang, J. Pseudogenization of the umami taste receptor gene tas1r1 in the giant panda coincided with its dietary switch to bamboo. Mol. Boil. Evol. 2010, 27, 2669-2673. [CrossRef] [PubMed]

40. Raliou, M.; Grauso, M.; Hoffmann, B.; Schlegel-Le-Poupon, C.; Nespoulous, C.; Débat, H.; Belloir, C.; Wiencis, A.; Sigoillot, M.; Bano, S.P. Human genetic polymorphisms in T1R1 and T1R3 taste receptor subunits affect their function. Chem. Senses 2011, 36, 527-537. [CrossRef] [PubMed]

41. Chen, Q.Y.; Alarcon, S.; Tharp, A.; Ahmed, O.M.; Estrella, N.L.; Greene, T.A.; Rucker, J.; Breslin, P.A.S.; Fernstrom, J.D.; Beauchamp, G.K. Perceptual variation in umami taste and polymorphisms in TAS1R taste receptor genes. Am. J. Clin. Nutr. 2009, 90, 770S-779S. [CrossRef] [PubMed]

42. Bird, A. DNA methylation patterns and epigenetic memory. Genes Dev. 2002, 16, 6-21. [CrossRef] [PubMed]

43. Liang, X.F.; Liu, J.K.; Huang, B.Y. The role of sense organs in the feeding behaviour of chinese perch. J. Fish Biol. 1998, 52, 1058-1067. [CrossRef]

44. McGaugh, J.L. Memory-A century of consolidation. Science 2000, 287, 248-251. [CrossRef] [PubMed]

45. Nader, K.; Schafe, G.E.; Le Doux, J.E. Fear memories require protein synthesis in the amygdala for reconsolidation after retrieval. Nature 2000, 406, 722-726. [CrossRef] [PubMed]

46. Alberini, C.M. Mechanisms of memory stabilization: Are consolidation and reconsolidation similar or distinct processes? Trends Neurosci. 2005, 28, 51-56. [CrossRef] [PubMed]

47. Brightwell, J.J.; Smith, C.A.; Neve, R.L.; Colombo, P.J. Long-term memory for place learning is facilitated by expression of cAMP response element-binding protein in the dorsal hippocampus. Learn. Mem. 2007, 14, 195-199. [CrossRef] [PubMed] 
48. Bourtchuladze, R.; Frenguelli, B.; Blendy, J.; Cioffi, D.; Schutz, G.; Silva, A.J. Deficient long-term memory in mice with a targeted mutation of the cAMP-responsive element-binding protein. Cell 1994, 79, 59-68. [CrossRef]

49. Tao, X.; Finkbeiner, S.; Arnold, D.B.; Shaywitz, A.J.; Greenberg, M.E. Ca ${ }^{2+}$ influx regulates BDNF transcription by a CREB family transcription factor-dependent mechanism. Neuron 1998, 20, 709-726. [CrossRef]

50. Yamada, K.; Mizuno, M.; Nabeshima, T. Role for brain-derived neurotrophic factor in learning and memory. Life Sci. 2002, 70, 735-744. [CrossRef]

51. Tyler, W.J.; Alonso, M.; Bramham, C.R.; Pozzo-Miller, L.D. From acquisition to consolidation: On the role of brain-derived neurotrophic factor signaling in hippocampal-dependent learning. Learn. Mem. 2002, 9, 224-237. [CrossRef] [PubMed]

52. Alberini, C.M.; Ghirardi, M.; Huang, Y.Y.; Nguyen, P.V.; Kandel, E.R. A molecular switch for the consolidation of long-term memory: cAMP—inducible gene expression. Ann. N. Y. Acad. Sci. 1995, 758, 261-286. [CrossRef] [PubMed]

53. Kandel, E.R. The molecular biology of memory storage: A dialogue between genes and synapses. Science 2001, 294, 1030-1038. [CrossRef] [PubMed]

54. Neale, J.H.; Klinger, P.; Agranoff, B. Camptothecin blocks memory of conditioned avoidance in the goldfish. Science 1973, 179, 1243-1246. [CrossRef] [PubMed]

55. Alberini, C.M. Transcription factors in long-term memory and synaptic plasticity. Physiol. Rev. 2009, 89, $121-145$. [CrossRef] [PubMed]

56. Countryman, R.A.; Kaban, N.L.; Colombo, P.J. Hippocampal $c$-fos is necessary for long-term memory of a socially transmitted food preference. Neurobiol. Learn. Mem. 2005, 84, 175-183. [CrossRef] [PubMed]

57. Bozon, B.; Davis, S.; Laroche, S. Regulated transcription of the immediate-early gene Zif268: Mechanisms and gene dosage-dependent function in synaptic plasticity and memory formation. Hippocampus 2002, 12, 570-577. [CrossRef] [PubMed]

58. Bozon, B.; Davis, S.; Laroche, S. A requirement for the immediate early gene Zif268 in reconsolidation of recognition memory after retrieval. Neuron 2003, 40, 695-701. [CrossRef]

59. Chaudhuri, A.; Matsubara, J.A.; Cynader, M.S. Neuronal activity in primate visual cortex assessed by immunostaining for the transcription factor Zif268. Vis. Neurosci. 1995, 12, 35-50. [CrossRef] [PubMed]

60. Worley, P.F.; Christy, B.A.; Nakabeppu, Y.; Bhat, R.V.; Cole, A.J.; Baraban, J.M. Constitutive expression of Zif268 in neocortex is regulated by synaptic activity. Proc. Natl. Acad. Sci. USA 1991, 88, 5106-5110. [CrossRef] [PubMed]

61. Powell, C.M. Gene targeting of presynaptic proteins in synaptic plasticity and memory: Across the great divide. Neurobiol. Learn. Mem. 2006, 85, 2-15. [CrossRef] [PubMed]

62. Dean, C.; Liu, H.; Dunning, F.M.; Chang, P.Y.; Jackson, M.B.; Chapman, E.R. Synaptotagmin-iv modulates synaptic function and long-term potentiation by regulating BDNF release. Nat. Neurosci. 2009, 12, 767-776. [CrossRef] [PubMed]

63. Oike, H.; Nagai, T.; Furuyama, A.; Okada, S.; Aihara, Y.; Ishimaru, Y.; Marui, T.; Matsumoto, I.; Misaka, T.; Abe, K. Characterization of ligands for fish taste receptors. J. Neurosci. 2007, 27, 5584-5592. [CrossRef] [PubMed]

64. Zhao, H.; Zhang, J. Mismatches between feeding ecology and taste receptor evolution: An inconvenient truth. Proc. Natl. Acad. Sci. USA 2012, 109, E1464. [CrossRef] [PubMed]

65. Dang, Y.; Gao, X.; Xie, A.; Wu, X.; Ma, F. Interaction between umami peptide and taste receptor T1R1/T1R3. Cell Biochem. Biophys. 2014, 70, 1841-1848. [CrossRef] [PubMed]

66. Mallick, H.N. Understanding safety of glutamate in food and brain. Indian J. Physiol. Pharmacol. 2007, 51, 216-234. [PubMed]

67. Niki, M.; Takai, S.; Kusuhara, Y.; Ninomiya, Y.; Yoshida, R. Responses to apical and basolateral application of glutamate in mouse fungiform taste cells with action potentials. Cell. Mol. Neurobiol. 2011, 31, 1033-1040. [CrossRef] [PubMed]

68. Jones, M.W.; French, P.J.; Bliss, T.; Rosenblum, K. Molecular mechanisms of long-term potentiation in the insular cortex in vivo. J. Neurosci. 1999, 19, RC36. [CrossRef] [PubMed]

69. Wang, Y.; Leung, F.C. Gc content increased at CpG flanking positions of fish genes compared with sea squirt orthologs as a mechanism for reducing impact of DNA methylation. PLoS ONE 2008, 3, e3612. [CrossRef] [PubMed] 
70. Pierron, F.; Baillon, L.; Sow, M.; Gotreau, S.; Gonzalez, P. Effect of low-dose cadmium exposure on DNA methylation in the endangered European eel. Environ. Sci. Technol. 2013, 48, 797-803. [CrossRef] [PubMed]

71. Xiao, J.; Song, C.; Liu, S.; Tao, M.; Hu, J.; Wang, J.; Liu, W.; Zeng, M.; Liu, Y. DNA methylation analysis of allotetraploid hybrids of red crucian carp (Carassius auratus red var.) and common carp (Cyprinus carpio L.). PLoS ONE 2013, 8, e56409. [CrossRef] [PubMed]

72. Wen, A.; You, F.; Sun, P.; Li, J.; Xu, D.; Wu, Z.; Ma, D.; Zhang, P. CpG methylation of dmrt1 and cyp19a promoters in relation to their sexual dimorphic expression in the japanese flounder Paralichthys olivaceus. J. Fish Boil. 2014, 84, 193-205. [CrossRef] [PubMed]

73. Xing, H.; Wang, C.; Wu, H.; Chen, D.; Li, S.; Xu, S. Effects of atrazine and chlorpyrifos on DNA methylation in the brain and gonad of the common carp. Comp. Biochem. Physiol. Pt. C 2015, 168, 11-19. [CrossRef] [PubMed]

74. Martinowich, K.; Hattori, D.; Wu, H.; Fouse, S.; He, F.; Hu, Y.; Fan, G.; Sun, Y.E. DNA methylation-related chromatin remodeling in activity-dependent $B d n f$ gene regulation. Science 2003, 302, 890-893. [CrossRef] [PubMed]

75. Bird, A.P.; Wolffe, A.P. Methylation-induced repression-Belts, braces, and chromatin. Cell 1999, 99, 451-454. [CrossRef]

76. Klose, R.J.; Bird, A.P. Genomic DNA methylation: The mark and its mediators. Trends Biochem. Sci. 2006, 31, 89-97. [CrossRef] [PubMed]

77. Robertson, K.D.; Jones, P.A. DNA methylation: Past, present and future directions. Carcinogenesis 2000, 21, 461-467. [CrossRef] [PubMed]

78. Watt, F.; Molloy, P.L. Cytosine methylation prevents binding to DNA of a HeLa cell transcription factor required for optimal expression of the adenovirus major late promoter. Genes Dev. 1988, 2, 1136-1143. [CrossRef] [PubMed]

79. Sarraf, S.A.; Stancheva, I. Methyl-CpG binding protein MBD1 couples histone H3 methylation at lysine 9 by SETDB1 to DNA replication and chromatin assembly. Mol. Cell 2004, 15, 595-605. [CrossRef] [PubMed]

80. Renaud, S.; Loukinov, D.; Abdullaev, Z.; Guilleret, I.; Bosman, F.T.; Lobanenkov, V.; Benhattar, J. Dual role of DNA methylation inside and outside of CTCF-binding regions in the transcriptional regulation of the telomerase hTERT gene. Nucleic Acids Res. 2007, 35, 1245. [CrossRef] [PubMed]

81. Jones, P.A. The DNA methylation paradox. Trends Genet. 1999, 15, 34-37. [CrossRef]

82. Jones, P.A. Functions of DNA methylation: Islands, start sites, gene bodies and beyond. Nat. Rev. Genet. 2012, 13, 484-492. [CrossRef] [PubMed]

83. Rountree, M.R.; Selker, E.U. DNA methylation inhibits elongation but not initiation of transcription in Neurospora crassa. Genes Dev. 1997, 11, 2383-2395. [CrossRef] [PubMed] 